Annales Geophysicae (2004) 22: 1019-1032

SRef-ID: $1432-0576 / \mathrm{ag} / 2004-22-1019$

(C) European Geosciences Union 2004

\title{
Quantitative magnetotail characteristics of different magnetospheric states
}

\author{
M. A. Shukhtina ${ }^{1}$, N. P. Dmitrieva ${ }^{1}$, and V. A. Sergeev ${ }^{1}$ \\ ${ }^{1}$ V. A. Fock Institute of Physics, St.-Petersburg State University, St.-Petersburg, Russia
}

Received: 21 February 2003 - Revised: 21 July 2003 - Accepted: 21 August 2003 - Published: 19 March 2004

\begin{abstract}
Quantitative relationships allowing one to compute the lobe magnetic field, flaring angle and tail radius, and to evaluate magnetic flux based on solar wind/IMF parameters and spacecraft position are obtained for the middle magnetotail, $X=(-15,-35) R_{E}$, using 3.5 years of simultaneous Geotail and Wind spacecraft observations. For the first time it was done separately for different states of magnetotail including the substorm onset (SO) epoch, the steady magnetospheric convection (SMC) and quiet periods $(\mathrm{Q})$. In the explored distance range the magnetotail parameters appeared to be similar (within the error bar) for Q and SMC states, whereas at $\mathrm{SO}$ their values are considerably larger. In particular, the tail radius is larger by $1-3 R_{E}$ at substorm onset than during $\mathrm{Q}$ and $\mathrm{SMC}$ states, for which the radius value is close to previous magnetopause model values. The calculated lobe magnetic flux value at substorm onset is $\sim 1 \mathrm{GWb}$, exceeding that at $\mathrm{Q}(\mathrm{SMC})$ states by $\sim 50 \%$. The model magnetic flux values at substorm onset and SMC show little dependence on the solar wind dynamic pressure and distance in the tail, so the magnetic flux value can serve as an important discriminator of the state of the middle magnetotail.
\end{abstract}

Key words. Magnetospheric physics (solar windmagnetosphere-interactions, magnetotail, storms and substorms)

\section{Introduction}

Interaction of the Earth's magnetic field with the solar wind plasma causes the bundles of magnetic field lines to extend in the anti-solar direction forming the magnetotail. To a large degree its properties are determined by the solar wind parameters. Now a great amount of magnetic measurements covering a wide range of solar wind/IMF conditions is available in different parts of magnetosphere. This allows one to construct statistical data-based magnetospheric models describ-

Correspondence to: M. A. Shukhtina

(mshukht@geo.phys.spbu.ru) ing the magnetospheric magnetic field for given external conditions, such as Tsyganenko (1996), Ostapenko and Maltsev (1997), Tsyganenko (2002). However, this approach is limited and these statistical models are principally unable to accurately predict the magnetic field variability. The basic reason is that, besides the solar wind parameters, the magnetospheric characteristics and dynamical evolution also depend on the previous evolution, as the magnetosphere can stay in different magnetospheric states. For example, during southward IMF the magnetosphere can either show large changes associated with substorm (passing through the growth phase, expansion and recovery phases, e.g. Russell and McPherron, 1973) or stay in the state of steady magnetospheric convection (Sergeev et al., 1996). This variability is ignored in the aforementioned statistical magnetospheric models by their design.

There exist event-oriented models which give a snap-shot of the part of the magnetosphere sufficiently covered with spacecraft observations (see the models for the growth phase, e.g. Pulkkinen et al., 1991, or steady convection, Sergeev et al., 1996). However, due to poor statistics these models cannot describe reliably the global configuration and separate the effects of external variability from the consequences of internal processes.

A large amount of the works studying the substorm effects in the magnetosphere (following basic papers by Fairfield and Ness, 1970, Russell and McPherron, 1973, Caan et al., 1973, Fairfield et al., 1981, etc.) allowed one to understand many basic features of substorm phenomenon; however, they had either a qualitative character or had very localized subjects or the considered spatial domain. Summarizing, we still have no quantitative empirical model to describe the differences of magnetospheric magnetic fields associated with different magnetotail states.

A step toward such a model is done in our study where we construct the statistical models of basic magnetotail parameters separately for three basic magnetospheric states. The quiet magnetotail $(\mathrm{Q})$ is a natural background state with little electromagnetic interaction (and little energy exchange) 
between the solar wind and the magnetotail. The steady magnetospheric convection (SMC) state is a basic state with intense interaction, in which the magnetosphere supports the plasma circulation in a steady-state fashion. Such a state is known to exist, but its magnetotail magnetic fields are rarely studied (most of the the existing information was summarized by Sergeev et al., 1996), so our task here is to obtain quantitative characteristics of this state and compare it to both the quiet state and the substorms.

The third state selected is the substorm onset (SO), the state just before the global energy dissipation starts explosively in the magnetotail. As compared to the later stages involving strong and complicated local perturbations, the magnetospheric configuration at the end of the growth phase is still expected to keep the smooth magnetic field distribution. At the same time, as a result of large-scale evolution, this configuration may considerably deviate from background properties, and our main interest will be to evaluate these differences in quantitative terms.

Our approach will be to construct the regression models for a few basic variables describing the magnetotail state, which can be observed or computed from simultaneous measurements in the tail and solar wind. Among them we choose the tail lobe magnetic field $B_{L}$ and the flaring angle $\alpha$ of the tail magnetopause which characterizes the interaction between the solar wind and the tail (and is computed from the force balance). These two parameters depend differently on the external factors. Following the southward IMF turning both considered parameters are known to increase, providing the lobe magnetic flux increase (Caan et al., 1973; Maezawa, 1975; Fairfield et al., 1981; Fairfield, 1985). On the other hand, the solar wind dynamic pressure $\left(P_{d}\right)$ variations influence them differently: enhanced $P_{d}$ increases the $B_{L}$ value (Nakai et al., 1991; Fairfield and Jones, 1996; Tsyganenko, 2000), but decreases the flaring angle (Nakai et al., 1991; Petrinec and Russell, 1996). As a result, the use of either $B_{L}$ or $\alpha$ is insufficient to describe the magnetospheric behavior, whereas their joint study helps to separate the effects of IMF and $P_{d}$ and gives a more complete description of the magnetospheric system. Based on the obtained relations for $\alpha$ it is possible to calculate the tail radius $\mathrm{R}_{T}$. A great advantage in knowing both parameters $\left(B_{L}\right.$ and $\left.\mathrm{R}_{T}\right)$ is the possibility to calculate the tail magnetic flux $\mathrm{F}$, a fundamental global parameter of the magnetotail.

A number of previous studies treated statistically as a function of distance and solar wind parameters either the lobe field variations (e.g. Behannon, 1968; Mihalov and Sonnet, 1968; Sonnet et al., 1971; Slavin et al., 1985; Nakai et al., 1991; Fairfield and Jones, 1996; Borovsky, 1998; Tsyganenko, 2000), or the magnetopause shape and size (e.g. Sibeck et al., 1991; Roelof and Sibeck, 1993; Petrinec and Russell, 1996; Shue et al., 1997, 1998). The empirical models (Tsyganenko, 1996, 2002) use the predefined magnetopause which changes self-similarly in shape (changing with the dynamic pressure but independent of the IMF, neglecting the well-known magnetopause flaring variations during substorms). Only Petrinec and Russell (1996) (there- after referred to as PR96) considered both variables together and combined them to obtain the magnetic flux estimates. We expand their approach by using a more extended data set and by doing such analysis for different magnetotail states separately.

\section{Data preparation and analysis}

\subsection{Data analysis and event selection}

Our approach is based on the tail approximation (Birn, 1987), in which $\partial / \partial Z=O(1), B_{y}, B_{z}, \partial / \partial X, \partial / \partial Y=O(\varepsilon)$ for $\varepsilon^{2}<<1$, providing the conservation of one-dimensional pressure balance, which allows one to compute both the lobe magnetic field $B_{L}$ and the magnetopause flaring angle $\alpha$. This dictates the choice of the distance range $\left(X<-15 R_{E}\right)$ in the tail where this approximation is valid.

The equivalent lobe magnetic field $B_{L}$ is computed from the magnetic field and ion plasma parameters $\left(n, T_{p}\right)$ in (or near) the tail plasma sheet measured at the Geotail (GT) spacecraft as:

$$
B_{L}^{2} / 2 \mu_{0}=B^{2} / 2 \mu_{0}+n k T
$$

where $T=1.14 T_{p}$, to take into account the electron contributions (assuming $T_{p} / T_{e}=7$, e.g. Baumjohann, 1993). Based on computed $B_{L}$ and on the solar wind parameters observed at Wind spacecraft (time-shifted to the Geotail location with $\left.\Delta t=\left(X_{G T}-X_{W i n d}\right) / V_{s w}\right)$, the flaring angle $\alpha$ is calculated from the pressure balance on the magnetopause as :

$0.88 P_{d} \sin ^{2} \alpha+B_{s w}{ }^{2} / 2 \mu_{0}+n_{p} k\left(T_{i s w}+T_{e s w}\right)=B_{L}{ }^{2} / 2 \mu_{0}$

where $B_{s w}$ is the interplanetary magnetic field, $n_{p}$ and $T_{i s w}$ are the observed solar wind ion parameters, assuming $T_{e s w}=T_{i s w}$. According to Newbury and Russell (1998), the best approximation for the solar wind electron temperature is $T_{e s w}=1.41 * 10^{5 \circ} \mathrm{K}$; the assumption $T_{e s w}=2 T_{i s w}$ is also often used. We compared $\alpha$ values calculated according to Eq. (2) using these three approximations and found the difference to be $\leq 0.1 \%$, so our assumption does not greatly affect the results. The coefficient 0.88 gives the ratio of the magnetosheath pressure to solar wind dynamic pressure for high solar wind Mach numbers (Newtonian approximation, e.g. Spreiter et al., 1966). As $\alpha$ isolines in the lobes deviate from the $X=$ const lines, the calculated $\alpha$ values correspond to spacecraft position and should further be recalculated to the corresponding magnetopause coordinates $X^{*}$ (see Sect. 2.3).

We used data between January 1995 and April 1998 when the Geotail spacecraft was in the magnetotail at $X<-15 R_{E}$ and $|Y|<15 R_{E}$. We used Geotail magnetic field and ion plasma moments available from the DARTS database with 12-s time resolution, computed the $B_{L}$ values, and then averaged them over 6 min to obtain the final $B_{L}$. Wind magnetic and plasma data from the solar wind with $\sim 1$-min resolution taken from CDAWeb were also averaged over $6 \mathrm{~min}$ after being shifted in time. The following input variables were selected in our model: 
(1) The solar wind dynamic pressure $P_{d}=1.94 *$ $10^{-6} n_{p} V_{s w}{ }^{2}$ (assuming $4 \%$ helium content as in Tsyganenko, 1996), with $P_{d}$ in $\mathrm{nPa}$, proton number density $n_{p}$ in $\mathrm{cm}^{-3}, V_{s w}$ in $\mathrm{km} / \mathrm{s}$. This is the basic parameter controlling the tail magnetic field (e.g. Fairfield and Jones, 1996), as well as the size of magnetotail (PR96).

(2) The "dayside merging" electric field $E_{m}=V_{s w}\left(B_{y s w}{ }^{2}+B_{z s w}^{2}\right)^{1 / 2} \sin ^{3} \Theta / 2$ (where $\Theta$ is the IMF clock angle in $Y Z$ plane). The power law index 3 was chosen as it typically gives the best correlation with the cross-polar cap potential drop (e.g. Boyle et al., 1997; Eriksson et al., 2000). It was taken to be averaged over the 60 min preceding the observation in accordance with the results of Bargatze et al. (1985), who revealed the 60-min interval presumably corresponding to the accumulation time of the magnetic flux in the tail. Though the SMC mode is a direct driven one and is assumed to correspond to the 20-min time scale according to Bargatze et al. (1985), we also used the 60-min averaging interval for the SMC events for joint formal description of all states. Note that the choice of the averaging interval is not crucial for the SMC regime, as the SMC data set is characterized by stable solar wind/IMF conditions.

(3) Geotail position in the magnetosphere. We used alternatively either the $X$ coordinate, or the geocentric distance in the equatorial plane $R=\left(X^{2}+Y^{2}\right)^{1 / 2}$ (which is $\sim\left(X^{2}+Y^{2}+\right.$ $\left.Z^{2}\right)^{1 / 2}$ for Geotail since $Z \sim 0$ ). The $R$-dependence is considered because lines of constant $B_{L}$ closely follow the $R=$ const lines (e.g. Fairfield and Jones, 1996; Tsyganenko, 2000). The $X$-dependence was considered because the magnetopause (characterized by the flaring angle) is supposed to be axisymmetric, with the symmetry axis coinciding with the $X$ axis; besides, we compare our results with the results of PR96 and other magnetopause models, where the $X$-dependence of the flaring angle and magnetotail radius were used.

All data is presented in a GSM coordinate system. Solar wind and magnetotail data are used together with ground indices and high-latitude magnetograms to select the events of different kind. Ground PC index with 5-min resolution from Thule was taken (for some periods when Thule data missed we used 1-min PC-index from Vostok station). SYM and $\mathrm{AE}$ indices with a 1-min resolution, together with the $\mathrm{PC}$ index were used to control the geoefficiency of solar wind structures detected by Wind and to select the magnetospheric state. We also used magnetograms from ground magnetic stations in three longitudinal sectors (IMAGE, CANOPUS, $210 \mathrm{MM}$ ) to check the substorm onsets.

To categorize the magnetospheric states we used the following formal criteria:

Quiet state (Q) We required $E_{m}<0.5 \mathrm{mV} / \mathrm{m}$ (also $\mathrm{PC}<0.5 \mathrm{mV} / \mathrm{m}$ and $\mathrm{AE}<50 \mathrm{nT}$ ) at the time of observation and at least $2-\mathrm{h}$ before. The $2 \mathrm{~h}$-long interval was chosen to avoid the effect of previous substorm activity, as it exceeds the time interval between substorm onset and the end of the recovery phase (about $\sim 1.5 \mathrm{~h}$ according to Fairfield et al., 1981, and Baker et al., 1994a). 2172 of the 6- min-long sam- ples from 48 events have been identified as belonging to the $\mathrm{Q}$ data set according to these criteria.

Steady Magnetospheric Convection (SMC) We required a substantial external driving $\left(E_{m}>0.5 \mathrm{mV} / \mathrm{m}\right.$, PC follows $E_{m}$ variations) without substorms during the preceding hour (both lobe field variations and $\mathrm{AE}$ index, as well as auroral zone magnetograms were checked). The lobe field variations associated with solar wind $P_{d}$ variations were allowed if they were within $5 \%$ of prediction by the statistical relationship from Fairfield and Jones (1996). 1412 6-min-long samples grouped in 53 events have been identified for this SMC data set.

Substorm onset (SO) As different from many previous studies, we base the onset definition primarily on the behavior of the lobe magnetic field. Namely, we looked through high-resolution data plots and visually searched for the isolated sharp $B_{L}$ decrease, usually accompanied by a sharp $B_{Z}$ increase/decrease at Geotail. It was required that corresponding negative magnetic bays in the $\mathrm{H}$ component on the night-side auroral stations or in the AL index with amplitude $>100$ nT were observed. By the name "isolated" we mean that the lobe field $B_{L}$ has recovered well after the previous substorm. Although multiple substorm intensifications are well known (multiple-onset substorms), we hope such an approach allowed us to select the situations when the magnetotail was close to the onset of global instability (Baker et al., 1999); this is somewhat similar to the description of the "main onset" by Hsu and McPherron (1998). Substorms inside the storm periods (registered $>2 \mathrm{~h}$ after the storm main phase commencement and/or corresponding to $\mathrm{SYM}<-25 \mathrm{nT}$ ) were excluded. With these criteria we selected 132 well-defined substorm onsets, thus the SO data set contains 132 6-min-long samples (a single sample for every event). Ninety-five out of 132 onsets were preceded by the distinct $B_{L}$ growth, 34 were not, and for 3 substorms we had gaps in the Geotail data for the preceding time interval.

Average characteristics of these data sets are presented in Table 1.

\subsection{Regression model for the lobe magnetic field and flar-} ing angle

Our output variables are $B_{L}$ and $\alpha$ calculated from Eqs. (1) and (2). Our input variables are the solar wind dynamic pressure $P_{d}$, the time-averaged dayside merging rate $E_{m}$, and the spacecraft position in the magnetotail (alternatively $R$ or $X$, sharing the same functional form). The correlation coefficients between different input parameters for each data set (given in Table 1) indicate that they can be considered independent in all cases, except for the pairs $R$ and $E_{m}, X$ and $E_{m}$ in the SMC data set. Further, we checked to what extent the outputs $B_{L}$ and $\alpha$ may be considered as independent variables. As $\alpha$ is calculated from Eq. (2) using $B_{L}$, one may suggest that the two quantities are highly correlated. In fact, the correlation coefficients between $B_{L}$ and $\sin ^{2} \alpha$ presented in Table 1 show that they are not strongly correlated; therefore, 
Table 1. Characteristics of different magnetospheric states.

\begin{tabular}{cccc}
\hline Data set & $\mathrm{Q}$ & SMC & SO \\
\hline \multicolumn{4}{c}{ Average parameters } \\
\hline Number of samples (intervals) & $2172(48)$ & $1412(53)$ & $132(132)$ \\
\hline$E_{m}, \mathrm{mV} / \mathrm{m}$ & 0.11 & 1.27 & 1.18 \\
$\mathrm{IMF} B_{z}, \mathrm{nT}$ & 2.1 & -2.1 & -1.9 \\
$P_{d}, \mathrm{nPa}$ & 2.18 & 2.53 & 2.76 \\
$R_{G T}, \mathrm{R}_{E}$ & 24.6 & 26.4 & 25.6 \\
$X_{G T}, \mathrm{R}_{E}$ & -23.0 & -24.6 & -24.4 \\
$B_{L}, \mathrm{nT}$ & 19.4 & 19.7 & 25.1 \\
$B_{z}, \mathrm{nT}$ & 2.5 & 4.3 & 0.5 \\
\hline Correlation coefficients between the input parameters \\
\hline$r_{R, P_{d}}$ & 0.012 & 0.109 & 0.079 \\
$r_{X, P_{d}}$ & 0.043 & 0.079 & 0.118 \\
$r_{R, E_{m}}$ & 0.024 & $0.455^{*}$ & -0.038 \\
$r_{X, E_{m}}$ & 0.0189 & $0.530^{*}$ & -0.038 \\
$r_{P_{d}, E_{m}}$ & -0.011 & -0.053 & 0.102 \\
\hline Correlation coefficients between the output parameters \\
\hline$r_{B L, \sin ^{2} \alpha}$ & 0.60 & 0.43 \\
\hline
\end{tabular}

their joint study gives more information than if they were analyzed separately.

The functional forms for $B_{L}$ and $\alpha$ were chosen based on the results of previous works. According to Fairfield and Jones (1996), Mihalov and Sonnet (1968), $B_{L}$ is well described by a power function of $R$. Though at large distances (tailward of $\sim 100 R_{E}$ ) the $B_{L}$ value should approach a constant (Slavin et al., 1985), it is unimportant for the $R$ range considered, so, unlike Fairfield and Jones (1996), we did not include a free term into the $R$-dependence. The $B_{L}$ dependence on $P_{d}$ was well described by a power law (Fairfield and Jones, 1996; Borovsky, 1998). The $B_{L}$ dependence on $E_{m}$ (not considered in the previous works) was assumed exponential: for $E_{m}=0$ the corresponding multiplier becomes 1 and the dependence is linear for small $E_{m}$ values, which looks reasonable. Therefore, the $B_{L}$ model is presented as

$$
\begin{aligned}
& B_{L}=a_{1} P_{d}^{a_{2}} R^{a_{3}} \exp \left(a_{4} E_{m}\right), \\
& B_{L}=A_{1} P_{d}^{A_{2}} X^{A_{3}} \exp \left(A_{4} E_{m}\right) .
\end{aligned}
$$

The exponential flaring angle dependence on $R$ and $X$ was chosen based on the results of PR96, Nakai et al. (1991), while its $P_{d}$-dependence was well presented by a power function. The $E_{m}$-dependence of $\sin ^{2} \alpha$ is chosen at Eq. (3). This gives

$$
\begin{aligned}
& \sin ^{2} \alpha=b_{1} P_{d}^{b_{2}} \exp \left(b_{3} R+b_{4} E_{m}\right) \\
& \sin ^{2} \alpha=B_{1} P_{d}^{B_{2}} \exp \left(B_{3} X+B_{4} E_{m}\right)
\end{aligned}
$$

To solve for Eqs. (3) and (4) we followed PR96 and took the logarithm of both sides of Eqs. (3), (4), obtaining two
Table 2. Regression and correlation coefficients obtained from the regression analysis.

\begin{tabular}{cccc}
\hline Lobe field $B_{L}$ model & $\mathbf{Q}$ & SMC & Substorm onset \\
\hline$a_{1}$ & 195.4 & 138.9 & 192.7 \\
$a_{2}$ & 0.336 & 0.268 & 0.275 \\
$a_{3}$ & -0.8059 & -0.680 & -0.739 \\
$a_{4}$ & -0.0315 & 0.027 & 0.0631 \\
$r$ & 0.923 & 0.781 & 0.927 \\
$r_{P_{d}}$ & 0.607 & 0.649 & 0.556 \\
$r_{R}$ & 0.719 & 0.429 & 0.666 \\
$r_{E_{m}}$ & 0.016 & -0.271 & 0.257 \\
\hline Flaring angle $\alpha$ model & & & \\
\hline$b_{1}$ & 0.5753 & 0.5881 & 0.7303 \\
$b_{2}$ & -0.2000 & -0.2664 & -0.4175 \\
$b_{3}$ & -0.0783 & -0.0749 & -0.0658 \\
$b_{4}$ & -0.1826 & -0.0313 & 0.0843 \\
$r$ & 0.889 & 0.760 & 0.891 \\
$r_{P_{d}}$ & 0.178 & 0.253 & 0.455 \\
$r_{R}$ & 0.838 & 0.655 & 0.802 \\
$r_{E_{m}}$ & 0.018 & 0.279 & 0.070 \\
\hline
\end{tabular}

$r$ is the multiple correlation coefficient; $r_{P_{d}}, r_{R}$ and $r_{E_{m}}$ are partial correlation coefficients with variations of $P_{d}, R$ or $E_{m}$.

linear systems for unknown coefficients $a_{1}, a_{2}, a_{3}, a_{4}$ and $b_{1}, b_{2}, b_{3}, b_{4}\left(A_{1}, A_{2}, A_{3}, A_{4}\right.$ and $\left.B_{1}, B_{2}, B_{3}, B_{4}\right)$. The obtained coefficients $a_{1}-a_{4}, b_{1}-b_{4}$ are presented in Table 2 (see also Table 3 for the rest coefficients).

The results in Table 2 confirm that the most important factors controlling both $B_{L}$ and $\alpha$ values are the spacecraft geocentric distance $R$ and solar wind dynamic pressure $P_{d}$. For the $B_{L}$ parameter the partial correlation coefficients corresponding to $R$ and $P_{d}$ are high $\left(\sim 0.6-0.7\right.$, except $r_{R}=0.429$ for SMC) and close to each other. For the $\alpha$ parameter $r_{R}>r_{P_{d}}, r_{P_{d}}>>r_{E_{m}}$ (the latter relation is violated for the SMC state, see below). Thus $R$ - and $P_{d}$-influence on $B_{L}$ are of the same order, while the flaring angle is more affected by $R$.

The influence of the dayside merging rate $\left(E_{m}\right)$ is less important, though more complicated to understand. Its negligible contribution during the quiet periods is expected. If we take $a_{4}=b_{4}=0$ for the $\mathrm{Q}$ data set, the multiple correlation coefficients will change by $<0.1 \%$ and variations of regression coefficients are also very small. Thereafter, we neglect this dependence for the quiet state data set (new coefficients are given in Table 3). In the SO data set $r_{E_{m}}=0.257$ for the $B_{L}$ parameter, so the influence of $E_{m}$ is not large but should be taken into account. The $\alpha$ dependence on $E_{m}$ is small $\left(r_{E_{m}}=0.07\right)$; its exclusion reduces the multiple correlation coefficient insignificantly (from 0.891 to 0.887 ) and changes the $b_{1}$ value by $\sim 10 \%$ from 0.73 to 0.81 . We keep the $E_{m^{-}}$ dependence in the final model for both $B_{L}$ and $\alpha$ at substorm onset.

The study of $E_{m}$ influence on $B_{L}$ and $\alpha$ for the SMC state is hampered by the notable mutual correlation between $R$ and 
Table 3. Final (versus initial) regression model.

\begin{tabular}{|c|c|c|c|c|}
\hline$B_{L}$ model & Q & SMC & SO & Previous works \\
\hline$a_{1}$ & 194.8(195.4) & $123.9(138.9)$ & 192.7 & \\
\hline$a_{2}$ & $0.336(0.336)$ & $0.262(0.268)$ & 0.275 & 0.25 ([1]), 0.37 ([2]), 0.35 ([3]) \\
\hline$a_{3}$ & $-.806(-.806)$ & $-.634(-.680)$ & -0.739 & $-0.767([4]),-1.2([5])$ \\
\hline$a_{4}$ & $0(-0.032)$ & $0(0.0267)$ & 0.0631 & \\
\hline$\sigma, \mathrm{nT}$ & $1.72(1.72)$ & $3.03(3.04)$ & 1.84 & \\
\hline$r$ & $0.922(0.923)$ & $0.782(0.781)$ & 0.927 & \\
\hline$\sigma_{[1]}, \mathrm{nT}$ & 4.01 & 4.18 & 2.79 & \\
\hline$r_{[1]}$ & 0.915 & 0.740 & 0.907 & \\
\hline$A_{1}$ & $125.7(125.8)$ & $96.5(117.9)$ & 126.4 & \\
\hline$A_{2}$ & $0.346(0.346)$ & $0.249(0.258)$ & 0.289 & \\
\hline$A_{3}$ & $-.686(-.686)$ & $-0.567(-.652)$ & -0.623 & $-0.3([6]),-0.577([7]),-0.53([8])$ \\
\hline$A_{4}$ & $0(-0.0136)$ & $0(0.0505)$ & 0.0641 & \\
\hline$\sigma, \mathrm{nT}$ & $2.13(2.12)$ & $2.88(2.86)$ & 2.09 & \\
\hline$r$ & $0.880(0.880)$ & $0.806(0.808)$ & 0.907 & \\
\hline \multicolumn{5}{|c|}{ Flaring angle model } \\
\hline$b_{1}$ & $.5641(.5753)$ & $.5977(.5881)$ & 0.7303 & \\
\hline$b_{2}$ & $-.2003(-.2000)$ & $-.2601(-.2664)$ & -0.4175 & $-0.47([5])$ \\
\hline$b_{3}$ & $-.0783(-.0783)$ & $-.0772(-.0749)$ & -0.06578 & \\
\hline$b_{4}$ & $0(-0.1826)$ & $0(-0.0313)$ & 0.0843 & \\
\hline$\sigma, \operatorname{deg}$ & $1.43(1.75)$ & $2.61(2.79)$ & 1.65 & \\
\hline$r$ & $0.892(0.889)$ & $0.759(0.760)$ & 0.891 & \\
\hline$B_{1}$ & $.4350(.4407)$ & $.4709(.4760)$ & 0.5692 & 0.788 ([PR96]) \\
\hline$B_{2}$ & $-.1742(-.1740)$ & $-.2966(-.2929)$ & -0.3899 & $-0.524([\mathrm{PR} 96])$ \\
\hline$B_{3}$ & $.0738(.0733)$ & $.0720(.0740)$ & 0.05988 & $0.085([\mathrm{PR} 96])$ \\
\hline$B_{4}$ & $0(-0.1310)$ & $0(.0234)$ & 0.0828 & \\
\hline$\sigma, \operatorname{deg}$ & $2.05(2.05)$ & $2.72(2.72)$ & 1.77 & \\
\hline$r$ & $0.825(0.822)$ & $0.764(0.764)$ & 0.877 & \\
\hline$\sigma_{P R}, \operatorname{deg}$ & 2.39 & 3.25 & 3.95 & \\
\hline$r_{P R}$ & 0.813 & 0.740 & 0.882 & \\
\hline
\end{tabular}

The values in parentheses correspond to the full regression model (including the $E_{m}$-dependence); $\sigma$ is the standard deviation; $\sigma_{[1]}, r_{[1]}, \sigma_{P R}, r_{P R}$ are the standard deviation and correlation coefficient given by [1] and PR96 correspondingly. [1] Fairfield and Jones (1996); [2] Borovsky (1998); [3] Tsyganenko (2000); [4] Mihalov and Sonnet (1968); [5] Nakai et al. (1991); [6] Behannon (1968); [7] Sonnet et al. (1971); [8] Slavin et al. (1985).

$E_{m}\left(X\right.$ and $\left.E_{m}\right)$ in this data set (marked by a star in Table 1$)$. Anyhow, the regression coefficients $a_{4}, b_{4}, B_{4}$, characterizing the $E_{m}$ contribution for the SMC data set are less than one half of the corresponding coefficients for the substorm data set (whereas the values of $A_{4}$ are comparable for two states), see Table 3 . Besides, the coefficients $a_{4}(0.0267)$ and $A_{4}(0.0505)$, as well as $b_{4}(-0.0313)$ and $B_{4}(0.0234)$ strongly differ from each other, though for independent input parameters the relations $a_{4} \sim A_{4}, b_{4} \sim B_{4}$ are expected (which is true for the SO array). These considerations show that the regression coefficients describing the $E_{m}$-dependence for SMC state are unstable and definitely are not reliable with the data set we have. Therefore, we decided to omit this dependence from the final model (although we do not claim that such dependence does not exist). The regression and correlation coefficients for the modified final models are presented in Table 3.

It follows from Table 3 that both $B_{L}$ and $\alpha$ are slightly better described by using $R$ as an input parameter (correlation coefficients are slightly higher, and the standard deviation 
slightly smaller than for $\mathrm{X}$ ) for $\mathrm{Q}$ and $\mathrm{SO}$, while $X$ is a more preferable input for the SMC data set (except the $\alpha$ standard deviation behavior). Generally, both $R$ and $X$ give high (approximately the same) correlation coefficients.

The final model is given by expressions $(3,4)$ with the coefficients from Table 3. Below we rewrite the final regression expressions for each data set in the more convenient form by normalizing the input variables to their average values:

\section{Quiet-time data set}

$$
\begin{aligned}
& B_{L}=19.8\left(P_{d} / 2.5\right)^{0.336}(R / 25)^{-0.806} \\
& \alpha=\arcsin \left(\left(0.4696\left(P_{d} / 2.5\right)^{-0.20} 0.1423^{R / 25}\right)^{1 / 2}\right)
\end{aligned}
$$

\section{Steady convection data set}

$$
B_{L}=20.5\left(P_{d} / 2.5\right)^{0.262}(R / 25)^{-0.634}
$$$$
\alpha=\arcsin \left(\left(0.4712\left(P_{d} / 2.5\right)^{-0.26} 0.1459^{R / 25}\right)^{1 / 2}\right)
$$

\section{Substorm onset data set}

$$
\begin{aligned}
B_{L}= & 23.0\left(P_{d} / 2.5\right)^{0.275}(R / 25)^{-0.739} 1.085^{E_{m} / 1.3} \\
\alpha= & \arcsin \left(\left(0.4982\left(P_{d} / 2.5\right)^{-0.42} 0.193^{R / 25}\right.\right. \\
& \left.\left.1.1158^{E_{m} / 1.3}\right)^{1 / 2}\right)
\end{aligned}
$$

or, with $X$-variable:

\section{Quiet}

$$
\begin{aligned}
& B_{L}=19.0\left(P_{d} / 2.5\right)^{0.346}(|X| / 25)^{-0.686} \\
& \alpha=\arcsin \left(\left(0.371\left(P_{d} / 2.5\right)^{-0.1742} 0.1580^{|X| / 25}\right)^{1 / 2}\right)
\end{aligned}
$$

\section{SMC}

$$
\begin{aligned}
& B_{L}=19.5\left(P_{d} / 2.5\right)^{0.249}(|X| / 25)^{-0.567} \\
& \alpha=\arcsin \left(\left(0.3588\left(P_{d} / 2.5\right)^{-0.2966} 0.1653^{|X| / 25}\right)^{1 / 2}\right)
\end{aligned}
$$

\section{Substorm onset}

$$
\begin{aligned}
B_{L}= & 22.2\left(P_{d} / 2.5\right)^{0.289}(|X| / 25)^{-0.623} 1.087^{E_{m} / 1.3} \\
\alpha= & \arcsin \left(\left(0.3982\left(P_{d} / 2.5\right)^{-0.3899} 0.2238^{|X| / 25}\right.\right. \\
& \left.\left.1.1136^{E_{m} / 1.3}\right)^{1 / 2}\right)
\end{aligned}
$$

\subsection{Magnetotail radius calculation}

The model expressions for the flaring angle $\alpha$ specify the tilt of axis-symmetric boundary (magnetopause) as a function of distance. Since $\tan \alpha=d R_{T} / d x$ (where $R_{T}$ is the tail radius), it can be formally integrated over $[0, X]$ to obtain the spatial variation of the tail radius for each data set as

$$
R_{T}(X)=R_{T 0}+\int_{0}^{X} \tan \alpha(x) d x,
$$

where $R_{T 0}$ is some initial value of the tail radius, hereafter supposed to be taken at the terminator $(X=0)$. Integration of (7) using (4b) gives:

$$
\begin{aligned}
& R_{T}(X)=R_{T 0}- \\
& \quad 2 / B_{3}\left(\arcsin \left(C \exp \left(0.5 B_{3} X\right)\right)-\arcsin (C)\right),
\end{aligned}
$$

where $C=\left(B_{1} P_{d}^{B_{2}} \exp \left(B_{4} E_{m}\right)\right)^{1 / 2}$, and $B_{1}, B_{2}, B_{3}, B_{4}$ coefficients are given in Table 3.

Following PR96, we ignore the $\mathrm{R}_{T 0}$ dependence on the IMF, and use their formula

$$
R_{T 0}=14.63\left(P_{d} / 2.1\right)^{-1 / 6}
$$

The choice of this $\mathrm{R}_{T 0}$ model will be later discussed and compared with other versions in Sect. 3.2.

Now we should take into account that the lines $B_{L}=$ const and $\alpha=$ const approximately correspond to magnetopause normals near the magnetopause, whereas $B_{L}$ isolines follow the lines $X=$ const in the central part of the tail. Therefore (see Figure 1), the $X$ value at Geotail position should be replaced with some new $X^{*}$ value at the magnetopause where the $B_{L}$ value is the same. In the region of the tail approximation this correction is small and with simple geometry of $B_{L}=$ const lines we can use it as $X^{*}=X-\Delta X$, where $\Delta X=\left(R_{T}-\left(Y^{2}+Z^{2}\right)^{1 / 2}\right) \sin \alpha \cos \alpha$, where $X, Y, Z$ are the coordinates of the observation point. Following PR96, with the corrected coordinates we can solve again the regression problem (finding new coefficients $B_{1}^{*}, B_{2}^{*}, B_{3}^{*},\left(B_{4}^{*}\right.$ for SO; Eq. 4b), calculate the new $R_{T}\left(X^{*}\right)$ function according to Eq. (8), and so on. Similar to PR96 we found the iteration procedure to converge quickly (the solution became stable already on the second-third iteration). The resulting regression models for the tail radius are given in Table 4.

\section{Discussion}

3.1 The pressure balance and its violations

Simple pressure balance in the magnetosphere and on the magnetopause are the basic assumptions of this work. The validity of the pressure balance assumption in the magnetosphere was explored theoretically (e.g. Rich et al., 1972; Birn, 1987) and checked experimentally (Fairfield et al., 
Table 4. Regression models for the tail radius using the terminator models from PR96 and from Shue et al. (1998) (the latter given in parentheses).

\begin{tabular}{ccccc}
\hline & Q & SMC & Substorm onset & Previous works \\
\hline$B_{1} *$ & $0.325(0.321)$ & $0.371(0.366)$ & $0.402(0.396)$ & $0.447($ PR96) \\
$B_{2} *$ & $-0.116(-0.120)$ & $-0.175(-0.182)$ & $-0.29(-0.29)$ & -0.524 (PR96) \\
$B_{3} *$ & $0.075(0.075)$ & $0.0781(0.0776)$ & $0.0612(0.0612)$ & $0.085($ PR96) \\
$B_{4} *$ & 0 & 0 & $0.076(0.080)$ & \\
\hline
\end{tabular}

1981; Baumjohann et al., 1990; Petrukovich et al., 1999). It was shown that in general vertical balance exists in the magnetotail tailward of $X \sim-15 R_{E}$, though there are some exceptions. For example, the 1-D balance may be violated in flux-rope-like structures (plasmoids and Traveling Compression Regions, TCRs, e.g. Slavin et al., 1984). Such structures, which are several minutes long and associated with a bipolar $B_{z}$-variation, are often observed close to substorm onset (e.g. Maezawa, 1975). Another kind of anomalous event is reported by Petrukovich et al. (1999), who observed 3 cases of long ( $\geq 10 \mathrm{~min}$ ) pressure pulses in the equatorial plasma sheet not seen in the tail lobe at the end of the substorm growth phase. Such rare observations were interpreted as a result of a collision of earthward and tailward flows in the plasma sheet, leading to the local plasma sheet thickening. We took care to avoid such problems by inspecting Geotail data with a 2-min resolution. When such pressure peaks were found before substorm onsets, the events were "cut" (in 2 out of 132 selected substorms the $B_{L}$ value after or before the pulse was taken) or discarded (for pulses longer than 5$10 \mathrm{~min})$.

The pressure balance along the magnetopause normal was demonstrated experimentally in PR96 (their Fig. 3). The validity of this assumption is indirectly supported by a good coincidence of the magnetopause shape obtained in PR96 (where the pressure balance was a principal assumption like in our Sect. 2.3), with the statistics of observed magnetopause positions (Safrankova et al., 2002; Yang et al., 2002).

3.2 Comparison of $B_{L}, \alpha$ and $R_{T}$ models with previous results

$B_{L}$ dependence on the geocentric distance $R$ (or $X$ coordinate), $P_{d}$, IMF and some other parameters was previously studied by Behannon (1968), Mihalov and Sonnet (1968), Sonnet et al. (1971), Slavin et al. (1985), Nakai et al. (1991), Fairfield and Jones (1996), Borovsky (1998), Tsyganenko (2000). According to Table 3 the power indices describing the $B_{L}$ dependence on $P_{d}\left(a_{2}, A_{2}\right)$ and $R / X\left(a_{3} / A_{3}\right)$, on average correspond well to previous results, except Behannon (1968) for $A_{3}$ and Nakai et al. (1991) for $a_{3}$. The latter discrepancy is due to the different distance range (10 $R_{E}$, $22 R_{E}$ ), analyzed in Nakai et al. (1991) (see discussion in Fairfield and Jones, 1996). The Behannon (1968) $A_{3}$ value is underestimated as compared to values obtained in all previous works.
The agreement of our $\alpha$ model with previous results is not as good. On average, our $\alpha$ values show a weaker dependence on the distance and $P_{d}$ than in Nakai et al. (1991), PR96. The discrepancy of $B_{3}$ values could be partly due to the different $X$ range $\left(-10 R_{E},-22 R_{E}\right)$ used in these studies. As for the dynamic pressure dependence, the $b_{2}, B_{2}$ quantities differ significantly for different states, being much larger (and closer to the previous results) for the substorm data set than for the $\mathrm{Q}$ and SMC ones.

The IMF $\left(E_{m}\right)$ influence on the tail parameters cannot be directly compared with other works, as they used other functions describing IMF contribution and also, this influence is of the second order of magnitude as compared to the influence by $R$ and $P_{d}$. However, we can compare $B_{L}$ and $\alpha$ values calculated with our model (Eqs. 5 and 6 and Table 3 ) with the expressions from Fairfield and Jones (1996) and PR96 (including their IMF-dependent terms) for our Q, SMC and SO data sets. These results are also presented in Table 3. Our correlation coefficients are, on average, slightly (by $\sim 1-3 \%$ ) higher than those given by the models considered. However, the standard deviations in the previous models (Fairfield and Jones, 1996, PR96) are notably (sometimes more than twice) larger due to systematic differences in our three data sets (see Sect. 3.3).

When calculating the tail radius, some approximations were made, particularly, (a) we used a simplified procedure to compute the corresponding magnetopause $X^{*}$ coordinate, and (b) we extrapolated the tail radius model (based on observations made at $X<-15 R_{E}$ ) until the terminator when using Eq. (8). Therefore, the results for the tail radius require a careful comparison with existing observation-based magnetopause models.

There is still a choice in selection of the terminator magnetopause model. We used the simple model (Eq. 9) from PR96 ignoring the IMF-dependence of $R_{T 0}$, whereas Shue et al. (1998) included the IMF effects together with dynamic pressure dependence. To check the validity of our choice we included the additional input parameter, 6-min average IMF $B_{z}$, into our data sets, and repeated the iterative procedure for both variants of the terminator model. The resulting coefficients describing the magnetopause shape (see Table 4) practically coincide for two terminator models tried, so the choice of either of these models is justified.

We also checked the influence of the assumed $\alpha$ isolines' shape on the obtained $R_{T}$ value. It turned out that this shape does not considerably change the result, though the chosen 


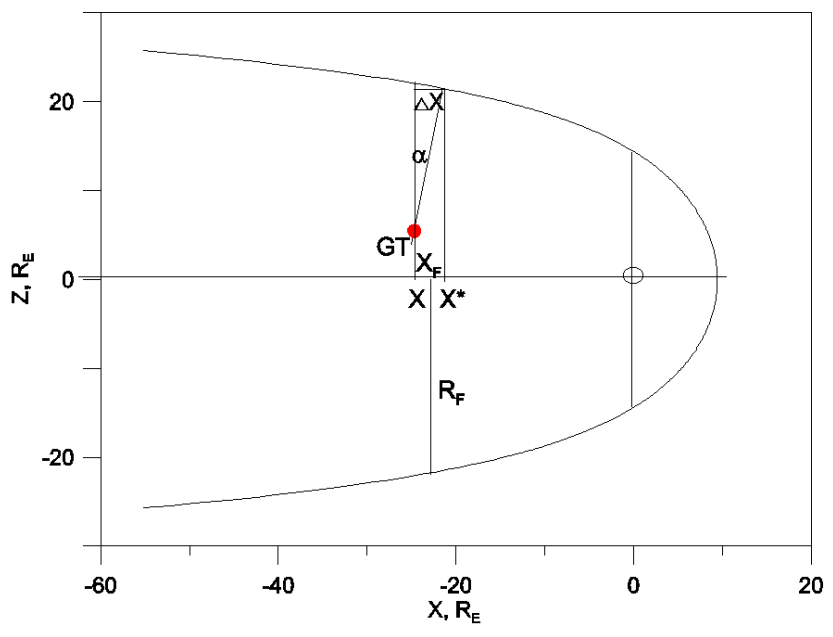

Fig. 1. The scheme presenting the geometry of Geotail measurements for the day-night meridian. $X$ is the Geotail position, $X^{*}-$ the magnetopause coordinate, corresponding to the same $B_{L} / \alpha$ values, $X_{F}=0.5\left(X+X^{*}\right)$ and $R_{T}\left(X_{F}\right)=0.5\left(R_{T}(X)+R_{T}\left(X^{*}\right)\right)-$ the quantities used when calculating the tail magnetic flux.

variant with circular symmetry of isolines (Fig. 1) somewhat better agrees with previous magnetopause models.

Figures $2 \mathrm{a}-\mathrm{c}$ demonstrate the $R_{T}$ dependence on the inputs $P_{d}, X$, and $E_{m}$ for the present model compared with previous ones, with other input parameters having their fixed average values. Note that other models use the IMF $B_{z}$ input instead of $E_{m}$, and the relationship between these two variables may vary. In Figs. $2 \mathrm{a}$ and $\mathrm{b} E_{m}$ and $B_{z}$ have their average values for $\mathrm{SO}$ and SMC $(1.3 \mathrm{mV} / \mathrm{m}$ and $-2 \mathrm{nT})$, whereas in Fig. $2 c$ the $B_{z}$ value is calculated from $E_{m}$ assuming $V_{s w}=400 \mathrm{~km} / \mathrm{s}, \Theta=\pi$, i.e. IMF $B_{y}=0$. According to Fig. 2 our $\mathrm{Q}$ and SMC $R_{T}$ values everywhere lie between those given by other models (PR96, Sibeck et al., 1991 (S91); Roelof and Sibeck, 1993 (RS93); Shue et al., 1998), with the largest discrepancy $\left(\sim 2 R_{E}\right)$ being observed with PR96 for $P_{d}=6 \mathrm{nPa}$ and with RS93 for IMF $B_{z}=-5 \mathrm{nT}$. Two dashed curves in Fig. 2b showing the empirical magnetopause for dynamic pressure values bracketing our average value (2.5 nPa) according to Sibeck et al. (1991) also have our Q and SMC curves between them. Such comparisons allow us to be sure that numerically our magnetopause model has a good agreement with observed magnetopause positions, at least in the input parameters range near their average values, where most of the empirical data points come from. The SO magnetotail models differ significantly from the empirical models and from our Q, SMC models, which is discussed below.

\subsection{Magnetotail parameters in different dynamical states}

We have already noticed the large differences between the magnetotail parameters at substorm onset and in the dynamically equilibrium states (quiet and steady convection); now we discuss these differences in quantitative terms. We first analyze the behavior of basic output variables, the lobe field and tail flaring angle, which is given by the coefficients in Table 3 and is illustrated in Figs. 3 and 4. Here we show the partial contributions of variations related to the distance $(R)$, solar wind pressure $\left(P_{d}\right)$ (and the $E_{m}$-variation, only for substorm data set). The top panel in each of Figs. 3 and 4 shows the variations in our Q, SMC, SO models (with other parameters fixed to their average values), with the error bars showing the standard deviations in each data set. The remaining plots illustrate each of these three models, as well as the scattering of data points. To produce these plots (to suppress the scatter due to variations of other input variables), the $B_{L}$ and $\alpha$ values in each point were corrected according to the regression model (with the values of other variables reduced to their average values given in Table 1 ).

We emphasize that the scatter in $B_{L}(\mathrm{R}), B_{L}\left(P_{d}\right), \alpha(R)$ plots is small (corresponding partial correlations in Table 2 are high) for all states, so these dependencies are well defined, especially for Q and SO states. The $\alpha\left(P_{d}\right)$ plot is characterized by substantially larger scatter. Finally, the $E_{m}$ dependence of $B_{L}$ is characterized by small $(0.26)$ partial correlation coefficient, whereas for $\alpha\left(E_{m}\right)$ dependence the correlation is negligible $(0.07)$.

The next thing to emphasize is that the $B_{L}$ and $\alpha$-values for the SMC and Q data sets taken at the same distance and with the same solar wind dynamic pressure practically coincide within the error bars. The scatter for the SMC data set is larger, but the average behavior is well defined. In a case study of ISEE- 1 observations at $X=-20 \mathrm{R}_{E}$ during a steady convection event, Sergeev and Lennartsson (1988) reported that the observed $B_{L}$ values for Q and SMC states were $19 \mathrm{nT}$ and (18-22) nT correspondingly, whereas at substorm onset they exceeded $25 \mathrm{nT}$. According to our model, $B_{L}$ values for $P_{d}=1.5 \mathrm{nPa}, R=20 \mathrm{R}_{E}, E_{m}=(0.95-2.4) \mathrm{mV} / \mathrm{m}$ (as in Sergeev and Lennartsson, 1988) are $19.6 \mathrm{nT}(\mathrm{Q})$, $20.6 \mathrm{nT}(\mathrm{SMC})$ and (25.0-27.4) nT (SO), in good agreement with these observations.

The third important feature is that the magnetotail at substorm onset has a well-defined state (parameters in Figs. 3 and 4 display a relatively low scatter), and its parameters are distinctly different from the Q, SMC data sets, with the difference being larger than the error bar and larger than the difference between the Q and SMC models. Although the increase in the tail lobe field and flaring angle is well expected from previous experience, this is the first quantitative model allowing one to compute the amount of tail lobe magnetic field (and magnetic flux) increase prepared just before the onset of explosive large-scale tail instability (e.g. Baker et al., 1999) at different external conditions.

Maezawa (1975) studied experimentally the tail radius increase during the substorm growth phase. According to his estimates, the inferred $R_{T}$ increase in the $X$ range $(-30,-70) R_{E}$ during the growth phase is between $0.5 R_{E}$ and $4 \mathrm{R}_{E}$, on average, being $1-2 \mathrm{R}_{E}$, which agrees with the difference between SO and Q, SMC $R_{T}$ values shown in our Figure 2. 


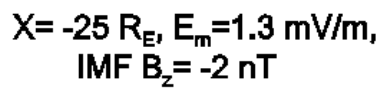

a

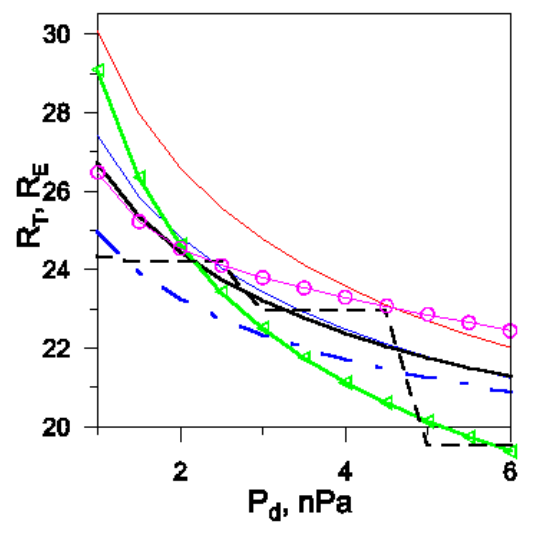

$P_{d}=2.5 n P a, E_{m}=1.3 \mathrm{mV} / \mathrm{m}$, IMF $B_{z}=-2 n T$

b

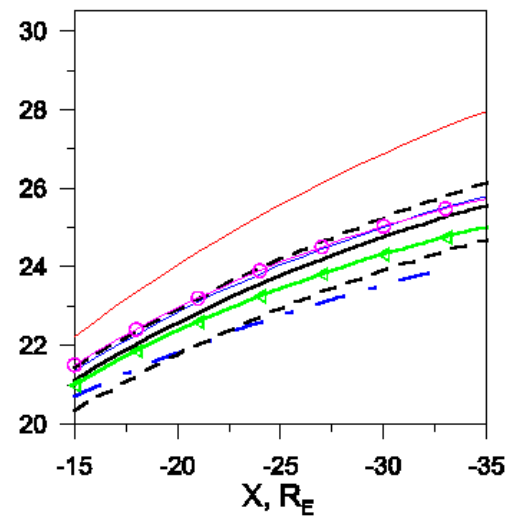

$P_{d}=2.5 n P a, X=-25 R_{E}$

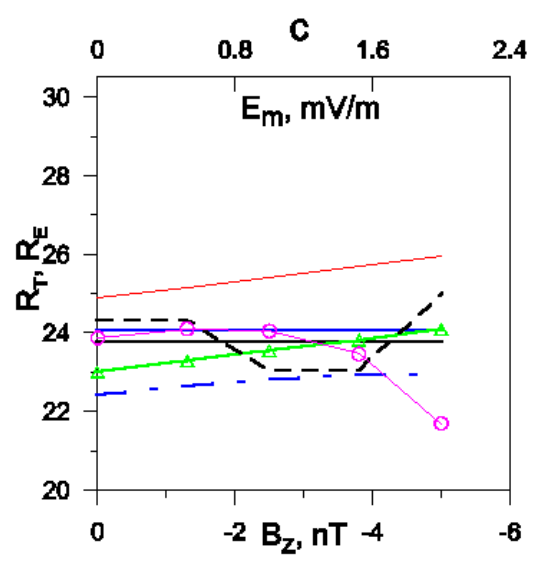

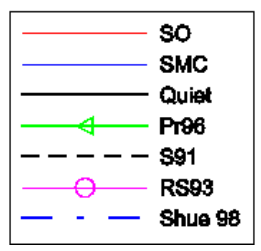

Fig. 2. Magnetotail radius dependence on $P_{d}, X, E_{m} / B_{z}$ for the present model compared with previous models.

\subsection{Magnetotail magnetic flux variations}

Having obtained the functions describing both the lobe magnetic field and tail radius variations, we may estimate the tail magnetic flux (considering one tail lobe) as

$F=B_{L} \pi R_{T}^{2} / 2$

When calculating this parameter, one should take into account the presumed circular geometry of $B_{L}=$ const lines. In our approximation, for $B_{L}$ (referred to the coordinate $X$ ) we determine $X^{*}=X-\Delta X$, compute $X_{F}=0.5\left(X+X^{*}\right)$ (as in Sect. 2.3, Fig. 1), calculate $R_{T}\left(X_{F}\right)=0.5\left(R_{T}(X)+R_{T}\left(X^{*}\right)\right)$ according to Eqs. (8) and (9) and Table 4, and use this value when computing Eq. (10). The results are presented in Fig. 5. Surprisingly, the so-computed $F$ values have almost no dependence on the distance in the tail, as well as on the dynamic pressure for the states with the strong coupling (substorms and SMC). In that sense the $F$ value itself is a welldefined global parameter which could be considered as the global state variable for the magnetotail. According to this figure, the value of the tail magnetic flux at substorm onset is about $1 \mathrm{GWb}$, exceeding that corresponding to $\mathrm{Q}$ state by $30-60 \%$ depending on $P_{d}$ and $X$ values. The SMC flux value $(\sim 0.7 \mathrm{GWb})$ coincides with the corresponding $\mathrm{Q}$ value within $\sim 15 \%$.

There were a few previous estimates of this quantity. In a similar manner Petrinec and Russell (1996) calculated the tail magnetic flux for several time intervals. They computed the tail radius from their model and used the $B_{L}$ value just measured by ISEE2 spacecraft in the tail lobe (neglecting the plasma sheet existence). They concluded that tailward of $15 \mathrm{R}_{E}$ the flux level dividing magnetotail states both followed and not followed by a substorm onset is $1.0-$ $1.4 \mathrm{GWb}$, somewhat larger than our estimate $\sim 0.8 \mathrm{GWb}$. In their CDAW9 case study Baker et al. (1994b) estimated the polar cap size variation during the substorm growth phase; it corresponds to the polar cap magnetic flux $\sim 0.8 \mathrm{GWb}$ at the beginning of the substorm growth phase and $\sim 1.1 \mathrm{GWb}$ at substorm onset in reasonable agreement with our numbers. Much smaller values $(0.46 \mathrm{GWb}$ during substorm conditions compared to $0.40 \mathrm{GWb}$ for average conditions) obtained by Newell et al. (2001) approach the lower limit of our Q/SMC estimates. Small difference between their substorm and nonsubstorm estimates is probably due to their substorm state definition, mixing the growth and expansion phases; for the same reason their average values are expected to correspond to $\mathrm{Q} / \mathrm{SMC}$ ones.

The additional magnetic flux stored in one tail lobe before the substorm onset according to Maezawa (1975) is $\Delta F \sim 0.05-0.13 \mathrm{GWb}$. This is much smaller than the difference with the SO and Q states, which is about $0.28 \mathrm{GWb}$ (0.15-0.4 GWb). However, our additional analysis (not presented here) showed that not all events considered had the compact well-defined growth phase, and that in cases with a clear growth phase, $B_{L}$ and $\alpha$ values at the growth phase beginning usually exceeded the quiet-time values, so the tail magnetic flux accumulated during the growth phase was 


\section{Lobe magnetic field}

\section{$R=25 R_{E}, E_{m}=1.3 \mathrm{mV} / \mathrm{m} \quad P_{d}=2.5 \mathrm{nPa}, E_{m}=1.3 \mathrm{mV} / \mathrm{m}$}
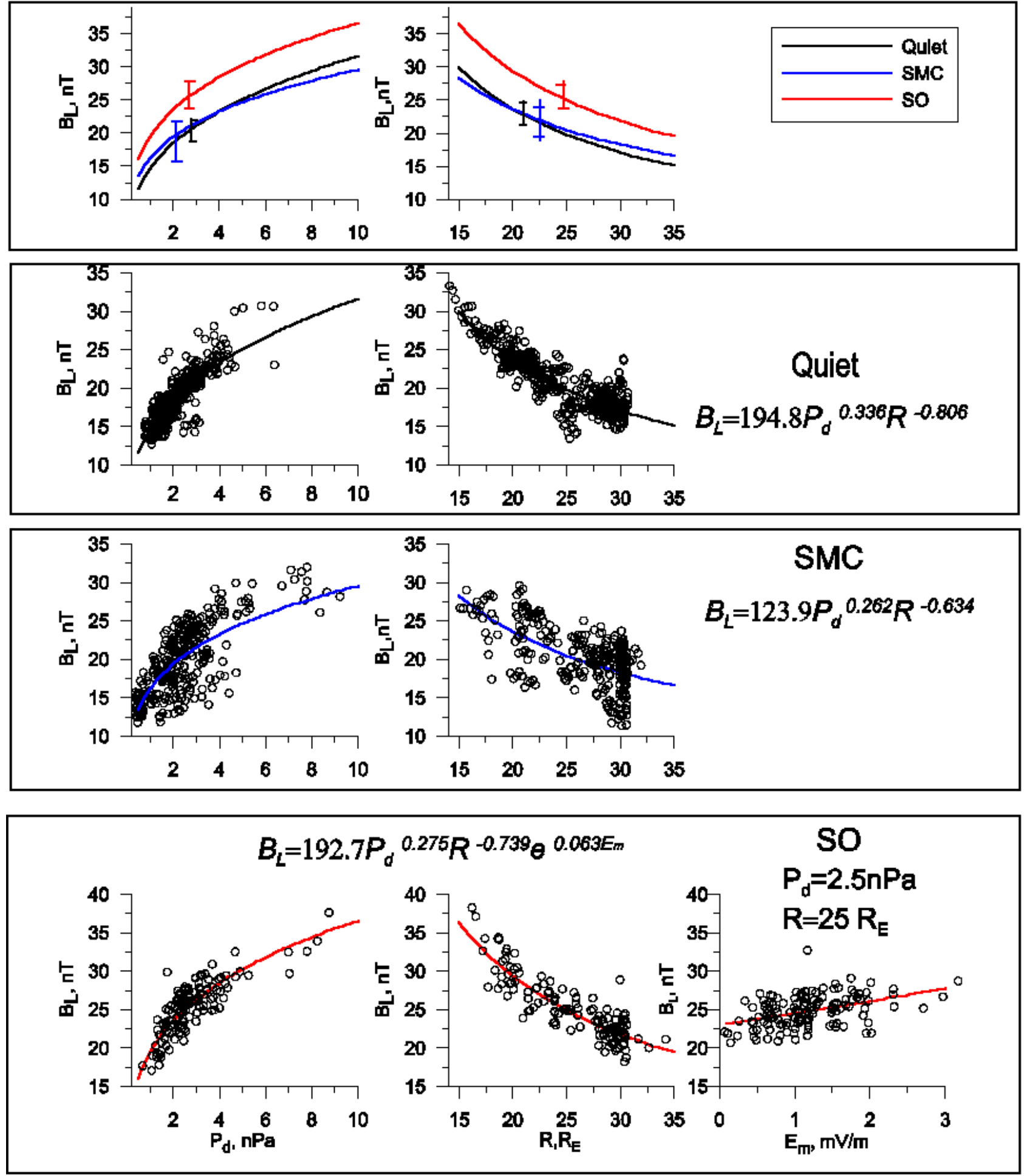

Fig. 3. The $B_{L}$-dependence on $P_{d}$ (left panel), on $R$ (central panel), and on $E_{m}$ (for SO, left panel) for three magnetospheric states discussed. The experimental points are reduced, every tenth point, every fifth point and all points being shown for Q, SMC and SO correspondingly. 


\section{Flaring angle}

\section{$R=25 R_{E}, E_{m}=1.3 \mathrm{mV} / \mathrm{m} \quad P_{d}=2.5 \mathrm{nPa}, E_{m}=1.3 \mathrm{mV} / \mathrm{m}$}
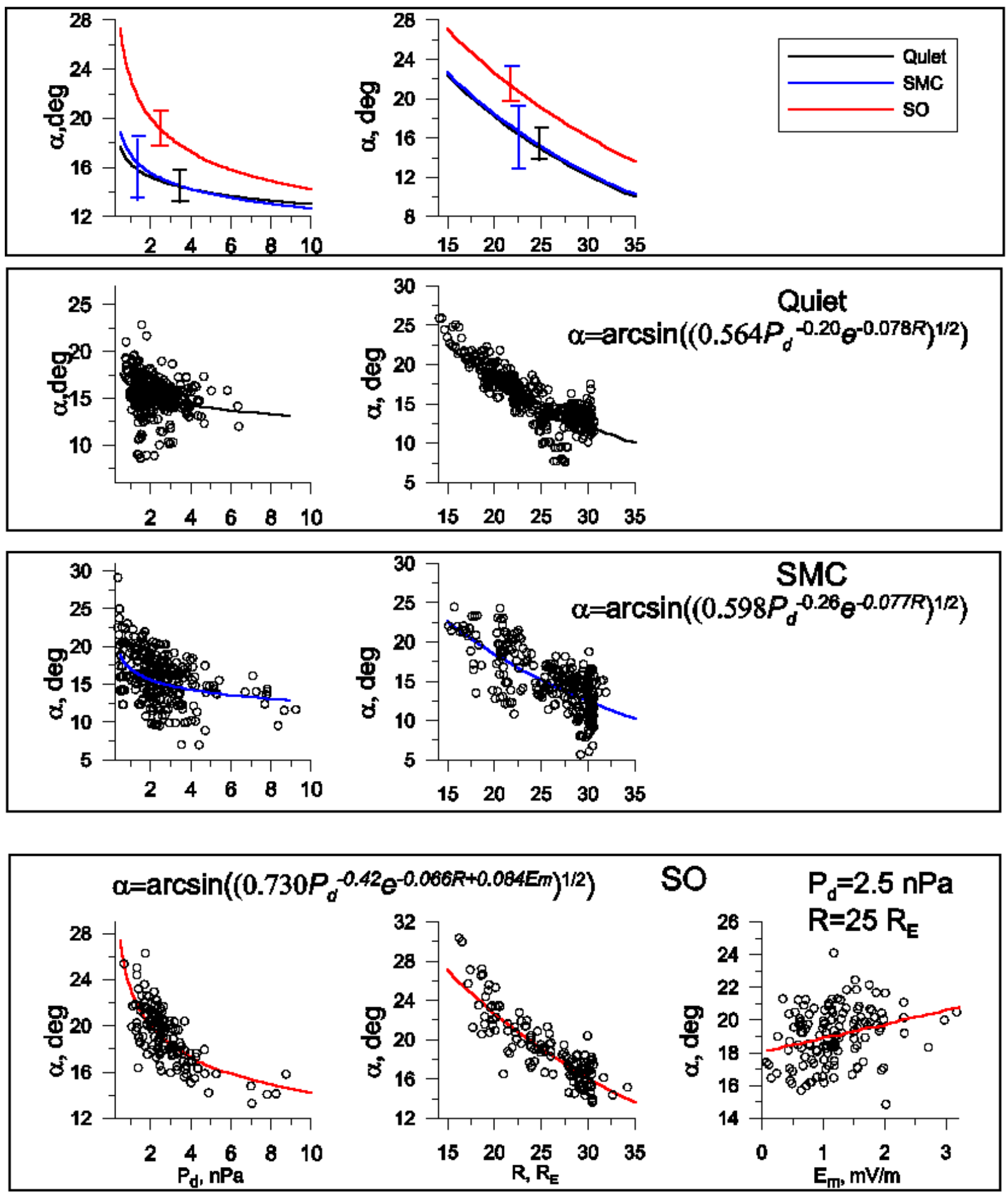

Fig. 4. The same as Fig. 3, but for the flaring angle. 

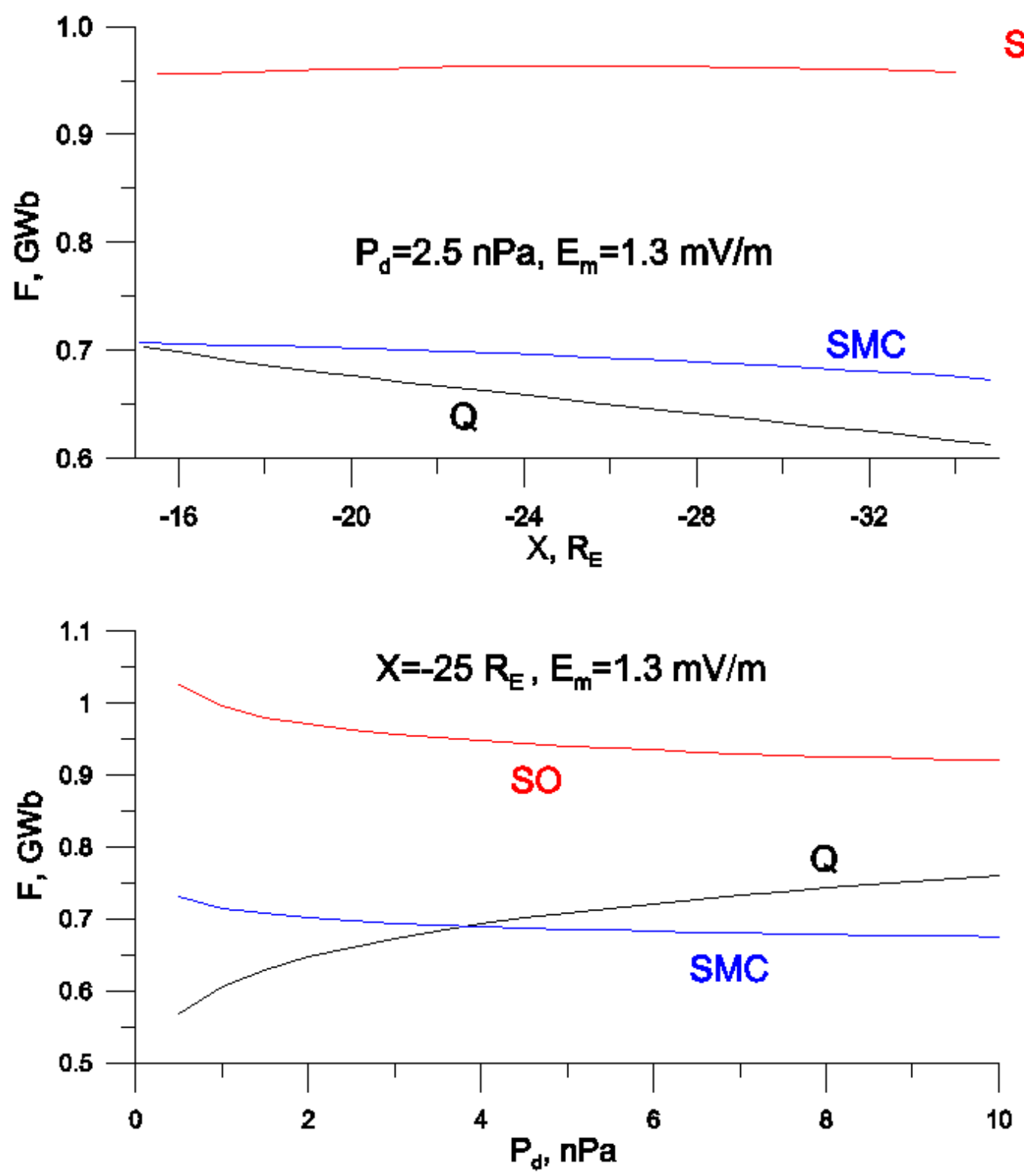

Fig. 5. $X$-and $P_{d}$-variations of the model magnetic flux for different magnetospheric states.

about $0.15-0.20 \mathrm{GWb}$, less than the differences with the SO and Q states, but still larger than the value given by Maezawa (1975). This discrepancy seems natural, as the estimates of Maezawa (1975) correspond to the $X$ range $(-30,-70) R_{E}$, where the $F$ value is expected to be lower than in the more eartward region due to magnetic flux closure through the magnetopause.

Rybal'chenko and Sergeev (1985) studied the rate of the tail lobe magnetic flux increase during the substorm growth phase in the $X$ range $(-10,-20) \mathrm{R}_{E}$. According to their results, for IMF $B_{z}=-3 \mathrm{nT}, V_{s w}=450 \mathrm{~km} / \mathrm{s}$ the corresponding $d F / d t=6 * 10^{4} \mathrm{~Wb} / \mathrm{s}$, which gives $\Delta F=0.22 \mathrm{GWb}$ for the growth phase duration of $60 \mathrm{~min}$, in reasonable agreement with our estimates.

It is also instructive to compare our estimates with those based on empirical information on the flux transfer rate. According to Dmitrieva and Sergeev (1983), for the growth phase of spontaneous substorms, the relationship $\tau B_{s}$ $\left(V_{s w} / 300\right)=300$ (where $\tau$ is the duration of southward IMF $B_{s}$ in minutes, $B_{s}$ in $\mathrm{nT}, V_{s w}$ in $\mathrm{km} / \mathrm{s}$ ) is valid. The left side of this relationship multiplied by the length of the dayside reconnection line $L$ gives the merged solar wind magnetic flux value: $F_{m}=L V_{s w} \tau B_{s}$. The $L$ value can be estimated from the cross-tail potential difference $\Phi$; according to Weimer et al. (1992), its average value during $30 \mathrm{~min}$ before substorm onset is $70 \mathrm{kV}$. For our average $E_{m}=1.3 \mathrm{mV} / \mathrm{m}$ we obtain $L=\Phi / E_{m}=8.5 \mathrm{R}_{E}$, which gives $F_{m}=0.29 \mathrm{GWb}$. This value is close to our upper limit estimate $(0.3 \mathrm{GWb}$ difference between $\mathrm{SO}$ and Q), but is about twice larger than the actual $\Delta F$ discussed above. Such a relationship is expected in the real system, where a part of the tail magnetic flux is circulating back to the dayside magnetopause. 
Holzer and Slavin (1979) estimated the value of magnetic flux $F_{m}$ merged on the dayside during a 40-minute period of $B_{s}=-4.5 \mathrm{nT}, V_{s w}=500 \mathrm{~km} / \mathrm{s}$. Note that the quantity $\tau B_{s}$ $\left(V_{s w} / 300\right)$ exactly equals 300 , so the input conditions are just the same as considered above. Their estimates gave $F_{m}=0.21 \mathrm{GWb}$, in reasonable agreement with our estimates.

Our flux estimates are the upper limits, since Eq. (10) neglects the existence of the plasma sheet (where the magnetic field is smaller). Taking into account that average plasma sheet half-thickness is $\mathrm{h} \sim 3 \mathrm{R}_{E}\left(\sim 2 \mathrm{R}_{E}\right.$ in the tail center and $\sim 4 \mathrm{R}_{E}$ near the flanks) and suggesting that the magnetic field changes linearly between the neutral sheet and the lobe/plasma sheet boundary, the ratio $\chi$ of magnetic flux in the plasma sheet to the one given by Eq. (10) is $\chi=2 h / \pi$ $R_{T}$. With $R_{T} \sim 24 \mathrm{R}_{E}, \quad \chi \sim 0.08$, which can easily be taken into account (but is possibly smaller than other uncertainties involved in the flux calculation).

\section{Conclusions}

We obtained quantitative regression relationships describing the variations of equivalent lobe magnetic field $B_{L}$, flaring angle $\alpha$ and tail radius $R_{T}$ in the middle tail $(X=[-15,-35]$ $\mathrm{R}_{E}$ ), depending on the distance in the tail, as well as on the solar wind dynamic pressure and dayside reconnection rate. With these relationships we were able to compute the tail magnetic flux. For the first time this was done separately for three distinct different states of the magnetotail, including the quiet state (low coupling between the tail and solar wind), the steady convection, and magnetotail state at substorm onset, just before the launch of the global tail instability.

In comparing different states of the magnetotail, we found that:

(1) All studied parameters $\left(B_{L}, \alpha\right.$ and $\left.R_{T}\right)$ nearly coincided (within the error bar) for the quiet and steady convection states, implying that magnetotail configuration in a dynamically equilibrium state is about the same in the middle tail region under different levels of external driving (therefore, under different levels of magnetospheric convection). In particular, the tail radius values $R_{T}$ for $\mathrm{Q}$ and SMC states are close to their values given by previous empirical magnetopause models.

(2) Magnetotail at substorm onset has a well-defined configuration showing a relatively small scatter. All studied parameters $\left(B_{L}, \alpha\right.$ and $\left.R_{T}\right)$ are considerably larger than during the dynamically equilibrium states (SMC and Q). Particularly, the tail radius is larger by $1-3 \mathrm{R}_{E}$, with the difference increasing tailward and decreasing with $P_{d}$.

(3) The estimated lobe magnetic flux $F$ in the midtail displays little changes with distance or with the solar wind dynamic pressure, so it could be considered as an important state parameter of the mid-magnetotail. The lobe magnetic flux at substorm onset is $\sim 1 \mathrm{GWb}$, exceeding that at $\mathrm{Q}$ (SMC) states by about $\sim 50 \%$.
Acknowledgements. We thank the teams of Geotail and Wind spacecraft for the observations made available via the Internet throughout DARTS and CDAWeb data bases. We are also grateful to the teams of IMAGE, CANOPUS and $210 \mathrm{MM}$ Internet sites. We thank WDC-C (Kyoto) for AE and SYM indices, O. Rassmussen for the Thule PC-index and O. A. Troshichev for providing 1-min PCindex from Vostok. This work was supported by the grants RFBR N03-05-64811, Grant of Ministry of Education of Russian Federation E02-8.0-3.

Topical Editor T. Pulkkinen thanks two referees for their help in evaluating this paper.

\section{References}

Baker, D. N,. Pulkkinen, T. I., Hones, E. W., Jr., Belian, R. D. McPherron, R. L., Angelopulus V.: Signatures of the substorm recovery phase at high-altitude spacecraft, J. Geophys. Res., 99, 10967, 1994a.

Baker, D. N, Pulkkinen, T. I., McPherron, R. L., and Clauer, C. R.: Multispacecraft study of substorm growth and expansion phase features using a time-evolving field model, in: Solar System Plasmas in Space and Time, Geophys. Monogr. Ser., edited by Burch, J. I., and Waite, J. H., Jr., 84, 101, AGU, Washington, D. C., 1994b.

Baker, D. N., Pulkkinen, T. I., Buchner, J., and Klimas, A. J.: Substorms: A global instability of the magnetosphere-ionosphere system, J. Geophys Res., 104, 14 601, 1999.

Bargatze, L. F., Baker, D. N., McPherron, R. L., Hones, E. W., Jr.: Magnetospheric impulse response for many levels of geomagnetic activity, J. Geophys. Res., 90, 6387, 1985.

Baumjohann, W., Paschmann, G., and Luhr, H.: Pressure balance between lobe and plasma sheet, Geophys. Res. Lett., 17, 45, 1990.

Baumjohann, W. G.: The near-Earth plasma sheet: an AMPTE/IRM perspective, Space Sci. Rev., 64, 141, 1993.

Behannon, K. W.: Mapping of the Earth's bow shock and magnetic tail by Explorer 33, J. Geophys. Res., 73, 907, 1968.

Birn, J.: Magnetotail equilibrium theory: the general threedimensional solution, J. Geophys. Res., 92, 11 101, 1987.

Borovsky, J. E., Thomsen, M. F., Elphic, R. C.: The driving of the plasma sheet by the solar wind. J. Geophys. Res., 103, 17617 , 1998.

Boyle, C. B., Reiff, P. H.,and Harrison, M. R.: Empirical polar cap potentials, J. Geophys. Res., 102, 111, 1997.

Caan, M. N., McPherron, R. L., and Russell, C. T.: Solar wind and substorm related changes in the lobes of geomagnetic tail, J. Geophys. Res., 78, 8087, 1973.

Coronoti, F. V. and Kennel, C. F.: Changes in magnetospheric configuration during the substorm growth phase, J. Geophys. Res., 77, 3361, 1972.

Dmitrieva, N. P. and Sergeev, V. A.: Spontaneous and triggered onset of substorm expansion and duration of the substorm growth phase, Geomagn. Aeron., Engl. Transl., 23, 474, 1983.

Eriksson, S., Ergun, R. E., Carlson, C. W., and Peria, W.: The crosspolar cap potential drop and its correlation to the solar wind, J. Geophys. Res., 105, 18 639, 2000.

Fairfield, D. H. and Ness, N. F.: Configuration of the geomagnetic tail during substorms, J. Geophys. Res., 75, 7032, 1970.

Fairfield, D. H., Lepping, R. P., Hones, E. W., Jr., Bame, S. J., and Asbridge, J. R.: Simultaneous measurements of magnetotail dynamics by IMP spacecraft, J. Geophys. Res., 86, 1396, 1981. 
Fairfield, D. H.: Solar wind control of magnetospheric pressure (CDAW6), J. Geophys. Res., 90, 1201, 1985.

Fairfield, D. H., and Jones, J.: Variability of the tail lobe field strength, J. Geophys. Res., 101, 7785, 1996.

Holzer, R. E., and Slavin, J. A: A correlative study of magnetic flux transfer in the magnetosphere, J. Geophys. Res., 84, 2573, 1979.

Hsu, T.-S. and McPherron, R. L.: The main onset of a magnetospheric substorm, in: Proceedings of Fourth International Conference on Substorms (ICS-4), Terra Scientific Publishing Company/Kluwer Academic Publishers, 79, 1998.

Maezawa, K.: Magnetotail boundary motion associated with geomagnetic substorms, J. Geophys. Res., 80, 3543, 1975.

Mihalov, J. D. and Sonnet, C. P.: The cislunar geomagnetic tail gradient in 1967, J. Geophys. Res., 73, 6837, 1968.

Nakai, H., Kamide, Y., and Russell, C. T.: Influences of solar wind parameters and geomagnetic activity on the tail lobe magnetic field, J. Geophys. Res., 96, 5511, 1991.

Newbury, J. A., Russell, C. T., Phillips, J. L., and Gary, S. P.: Electron temperature in the ambient solar wind: Typical properties and a lower bound at 1 AU, J. Geophys. Res., 103, 9553, 1998.

Newell, P. T., Liou, K., Sotirelis, T., and Meng, Ch.-I.: Polar ultraviolet imager observations of global auroral power as a function of polar cap size and magnetotail stretching. J. Geophys. Res., 106, 5895, 2001.

Ostapenko, A. A., and Maltsev., Y. P.: Relation of the magnetic field in the magnetosphere to the geomagnetic and solar wind activity, J. Geophys. Res., 102, 17 467, 1997.

Petrinec, S. M. and Russell, C. T.: Near-Earth magnetotail shape and size as determined from the magnetopause flaring angle, J. Geophys. Res., 101, 137, 1996.

Petrukovich, A. A., Mukai, T., Kokubun, S., Romanov, S. A., Saito, Y., Yamomoto, T., and Zelenyi, L. M.: Substorm-associated pressure variations in the magnetotail plasma sheet and lobe, J. Geophys. Res., 104, 4501, 1999.

Pulkkinen, T. I.: A study of magnetic field and current configurations in the magnetotail at the time of the substorm onset, Planet. Space Sci., 39, 833, 1991.

Pulkkinen, T. I., Baker, D. N., Fairfield, D. H., Pelinnen, R. J., Murphee, J. S., Elphinstone, R. D., McPherron, R. L., Fennel, J. F., Lopez, R. E., and Nagai, T.: Modelling the growth phase of a substorm using the Tsyganenko model and multispacecraft observations: CDAW-9, Geophys. Res. Lett., 18, 1963, 1991.

Rich, F. J., Vasyliunas, V. M., and Wolf, R. A.: On the balance of stresses in the plasma sheet, J. Geophys. Res., 77, 4670, 1972.

Roelof, E. C. and Sibeck, D. G.: Magnetopause shape as a bivariate function of interplanetary magnetic field $B_{z}$ and solar wind dynamic pressure: J. Geophys. Res., 98, 21 421, 1993.

Russell, C. T. and McPherron, R. L.: The magnetotail and substorms, Space Sci. Rev., 15, 205, 1973.

Rybal'chenko, V. V. and Sergeev V. A.: Rate of magnetic flux buildup in the magnetospheric tail, Geomagn. Aeron., 25, 378, 1985.

Safrankova, J., Nemecek, Z., Dusik, S., Prech, L., Sibeck, D. G., and Borodkova, N. N.: The magnetopause shape and location: a comparison of the Interball and Geotail observations with models, Ann. Geophysicae, 20, 301, 2002.
Sergeev, V. A., and Lennartsson, W.: Plasma sheet at $X \sim-20 \mathrm{R}_{E}$ during steady magnetospheric convection, Planet. Space Sci., 36, 353, 1988.

Sergeev, V. A., Pellinen, R. J., and Pulkkinen, T. I.: Steady Magnetospheric Convection: a review of recent results, Space Sci. Rev., 75, 551, 1996.

Shue, J.-H., Chao, J. K., Fu, H. C., Khurana, K. K., Russell, C. T., Singer, H. J., and Song, P.: A new functional form to study the solar wind control of the magnetopause size and shape, J. Geophys. Res., 102, 9497, 1997.

Shue, J.-H., Chao, J. K., Fu, H. C., Khurana, K. K., Russell, C. T., Singer, H. J., and Song, P.: Magnetopause location under extreme solar wind conditions, J. Geophys. Res., 103, 17691 , 1998.

Sibeck, D. G., Lopez, R. E., and Roelof, E. C.: Solar wind control of magnetopause shape, location and motion, J. Geophys. Res., 96, 5489, 1991.

Siscoe, G. L.: On the plasma sheet contribution to the force balance requirements in the geomagnetic tail, J. Geophys. Res., 77, 6230, 1972.

Slavin, J. A., Smith, E. J., Tsurutani, B. T., Sibeck, D. G., Siscoe, G. L., Singer H. J., Baker, D. N., Gosling, J. T., Hones, E. W., Jr., and Scarf, F. L.: Substorm associated traveling compression regions in the distant magnetotail: ISEE 3 geotail observations, study of average and substorm conditions in the distant magnetotail, Geophys. Res. Lett., 11, 6577, 1984.

Slavin, J. A., Smith, E. J., Sibeck, D. G., Baker, D. N., Zwickl, R. D., and Akasofu S.-I.: An ISEE 3 study of average and substorm conditions in the distant magnetotail, J. Geophys. Res., 90, $10875,1985$.

Sonnet, C. P., Mihalov, J. D., and Klozenberg, J. P.: The flux content and form of the geomagnetic tail, Cosmic Electrodyn., 2, 22 1971.

Spreiter, J. R, Alksne, A. Y., and Summers, A. L.: Hydromagnetic flow around the magnetosphere, Planet. Space Sci., 14, 223, 1966.

Tsyganenko, N. A.: Effects of solar wind conditions on the global magnetospheric configuration as deduced from data-based field models, Rur. Space Agency Spec. Publ., ESA SP-389, 181, 1996.

Tsyganenko, N. A.: Solar wind control of the tail lobe magnetic field as deduced from Geotail, AMPTE/IRM, and ISEE2 data, J. Geophys. Res., 105, 5517, 2000.

Tsyganenko, N. A.: A model of the near magnetosphere with a dawn-dusk asymmetry. 1. Mathematical structure, J. Geophys. Res., 107, 10.1029/2001JA000219, 2002.

Weimer, D. R., Kan, J. R., and Akasofu, S.-I.: Variations of the polar cap potential measured during magnetospheric substorms, J. Geophys. Res., 105, 3945, 1992.

Yang, Y.-H., Chao, J. K., Lin, C. H., Shue, J.-H., Wang, X.Y., Song, P., Russell, C. T., Lepping, R. P., and Lazarus, A. J.: Comparison of three magnetopause prediction models under extreme solar wind conditions, J. Geophys. Res., 107, 10.1029/2001IJA0000779, 2002. 